\title{
EDUCATION
}

\section{Cost Effective Implementation of a Doctorate in Clinical Laboratory Science Program}

\author{
NADINE A. FYDRYSZEWSKI, ELAINE M. KEOHANE
}

\begin{abstract}
The establishment of an advanced practice level in clinical laboratory science, the Doctorate in Clinical Laboratory Science (DCLS), has been a goal of the clinical laboratory science (CLS) community for more than 10 years. CLS educators at institutions of higher education are challenged to find the resources needed to provide the high-level and relevant didactic and experiential learning opportunities for medical laboratory scientists (MLS) to enter this new career path. Implementation of a DCLS program was achieved using a three phase approach, first adding a CLS track in an existing MS program, then expanding the breadth and depth of the curriculum into a MS in CLS, and using that strong foundation to complete the ladder to the DCLS level. This model also includes interdepartmental collaboration, interprofesional education (IPE), and faculty, course, and resource sharing. The three phase strategic approach provided the faculty and developmental resources and curricular foundation to implement the DCLS program in a cost-effective manner.
\end{abstract}

\begin{abstract}
ABBREVIATIONS: American Society for Clinical Laboratory Science (ASCLS), Doctorate in Clinical Laboratory Science (DCLS), Clinical Laboratory Science (CLS), Master of Science in Health SciencesClinical Laboratory Science Track (MSHS-CLS), Master of Science in Clinical Laboratory Science (MSCLS), Medical Laboratory Scientist (MLS), National Accreditation Agency for Clinical Laboratory Science (NAACLS), Rutgers- School of Health Related Professions (Rutgers-SHRP)
\end{abstract}

INDEX TERMS: Doctorate in Clinical Laboratory Science; Advanced Practice Doctorate, Program Development, CLS Career Ladder

Clin Lab Sci 2015;28(2):98
Nadine A. Fydryszewski, PhD, MLS(ASCP) ${ }^{C M}$, Rutgers, The State University of New Jersey, School of Health Related Professions, Newark, NJ

Elaine M. Keohane, PhD, MLS(ASCP) $)^{C M}$, Rutgers, The State University of New Jersey, School of Health Related Professions, Newark, NJ

Address for Correspondence: Nadine A. Fydryszewski, $\boldsymbol{P b D}, \boldsymbol{M L S}(\boldsymbol{A S C P})^{C M}$, Rutgers, The State University of New Jersey, School of Health Related Professions, 65 Bergen Street- SSB GB 20, Newark, NJ 07101-1709, 973-972-5089, fydrysna@shrp.rutgers.edu

\section{INTRODUCTION}

For more than 10 years the American Society for Clinical Laboratory Science (ASCLS) and the clinical laboratory science (CLS) community have supported the concept of a new CLS advanced practice level, the Doctorate in Clinical Laboratory Science (DCLS). ${ }^{1}$ The DCLS practitioners will extend their role beyond the laboratory to actively contribute to interprofessional health care teams as experts in clinical laboratory testing. They will partner with pathologists, laboratory directors, administrators, clinicians, and other health care providers to promote appropriate, effective, and efficient use of laboratory tests to improve patient outcomes and reduce unnecessary testing. They will be experts in collecting and analyzing the data needed to develop evidence-based laboratory practices such as appropriate reflex testing and patient-centered test algorithms. Their role outside of the laboratory will provide real-time and on-time expertise at the point of service including clinical rounding, consulting with clinicians regarding test ordering and interpretation, and interacting with patients and the public to promote understanding of laboratory tests.

In 2006 the National Accreditation Agency for Clinical Laboratory Science (NAACLS) published a special 


\section{EDUCATION}

addition of the NAACLS News dedicated to the DCLS, and established a program accreditation process for doctorate programs in CLS., ${ }^{2,3}$ Numerous publications address the need for the DCLS practitioner in healthcare and propose curricular models, growth, and projected outcomes. ${ }^{4-13}$ In Fall 2007, the CDC Division of Laboratory Systems convened a professionally facilitated meeting "The 2007 Institute: Managing for Better Health". This Institute addressed the wideranging goal of improving the integration of laboratory medicine within the health system. Of the four main goals identified at this meeting, one was:

"to institutionalize new models of clinical consultation provided by the laboratory medicine professionals to clinicians to guide their decisions about utilization of laboratory tests or services".

This goal addresses the CDC's vision of a collaborative effort between the laboratorian (DCLS) and a more consultative pathologist changing laboratory medicine's contribution to healthcare. Since the initial meeting, CDC has modified the initial four goals down to two. However, this goal has been maintained, emphasizing its importance. Subsequent to the Institute, CDC established the Clinical Laboratory Integration into Healthcare Collaborative $\left(\mathrm{CLIHC}^{\mathrm{TM}}\right)$ to investigate the education, communication and consultation needs of clinicians as they use laboratory services and interpret test results. At the latest meeting of CLIHC in 2014, the importance of consultation by pathologists and laboratorians led to a discussion of the need for models of successful consultation between clinicians and laboratory professionals. ${ }^{4}$ Practicing physicians are also seeking a more active collaboration with laboratorians. The following interview with a physician illustrates this need:

"If you had a magic wand to wave over the clinical laboratory, what would you change?

I would somehow bring the expertise from the clinical laboratory into our clinic. I am surrounded by physicians and scientists who have an exceptional knowledge base that I wish I could tap into at the point-of-care. No doubt, every provider has limits to his/her own knowledge, and collaboration with colleagues often leads to better care for patients." ${ }^{5}$
Surveys of the CLS professional community have demonstrated CLS professionals' interest in pursuing the DCLS. Doig and Beck (2008) surveyed 952 CLS professionals with 299 respondents (31\% response rate); $65.2 \%$ of respondents were interested in the DCLS as a career. ${ }^{14}$ Nadder (2011) reported of 1,452 respondents, $849(61 \%)$ were very interested or interested in completing a DCLS program, and 23\% envisioned starting a program as soon as one is offered. ${ }^{15}$ Through the efforts of the ASCLS Professional Doctorate Task Force established in 2005, which transitioned to the DCLS Oversight Committee in 2009, the CLS community has continued the journey toward the establishment of this new advanced practice degree and career path for medical laboratory scientists (MLS).

The CLS profession's efforts to forge a new career path are intrinsically tied to CLS educators at institutions of higher education. Offering a new degree program at a higher education institution presents numerous challenges at the institution and state level. Universities and the state division with oversight of higher education have diverse criteria and policies regulating the establishment of a new degree program. Obtaining institution and state approval has been challenging and may take several years to complete.

\section{PhD vs. PROFESSIONAL DOCTORATE}

CLS educators exploring the development of a DCLS program, as well as MLS interested in the DCLS as a career path should be aware of essential differences between a $\mathrm{PhD}$ and a professional doctorate. For educators, it is important to consider how the various degrees align with their university and department mission, goals, objectives, and outcomes. For the MLS seeking advanced education and career development, it is important to consider which degree best meets their career goals. The Rutgers, School of Health Related Professions (formerly University of Medicine and Dentistry of New Jersey until July 2013) convened a Practice Doctorate Task Force and conducted an extensive review of entry level and advanced practice doctorate degree components of discipline specific practice doctorates. This review included the Doctorate of Physical Therapy (DPT), Doctorate in Clinical Nutrition (DCN), and the Doctorate of Nursing Practice (DNP), as well as other practice doctorates. In addition, several documents and position papers related to professional and practice doctorates were 
reviewed. ${ }^{16,17}$ Table 1 compares key educational requirements of a $\mathrm{PhD}$ vs. an advanced professional doctorate (such as the DCLS and DCN) and the entrylevel professional doctorate (such as the DPT and Doctor of Pharmacy or Pharm D). PhD programs focus on acquisition of research skills in preparation for careers in research organizations and academia. These programs include a greater number of research credits including the candidacy exam, hypothesis-driven, focused research, and dissertation requirements. In contrast, professional doctorate programs focus on acquisition of clinical skills in preparation for professional board certification, but does include requirements for translational and outcomes research.

Table 1. PhD vs. Practice Doctorate Degrees

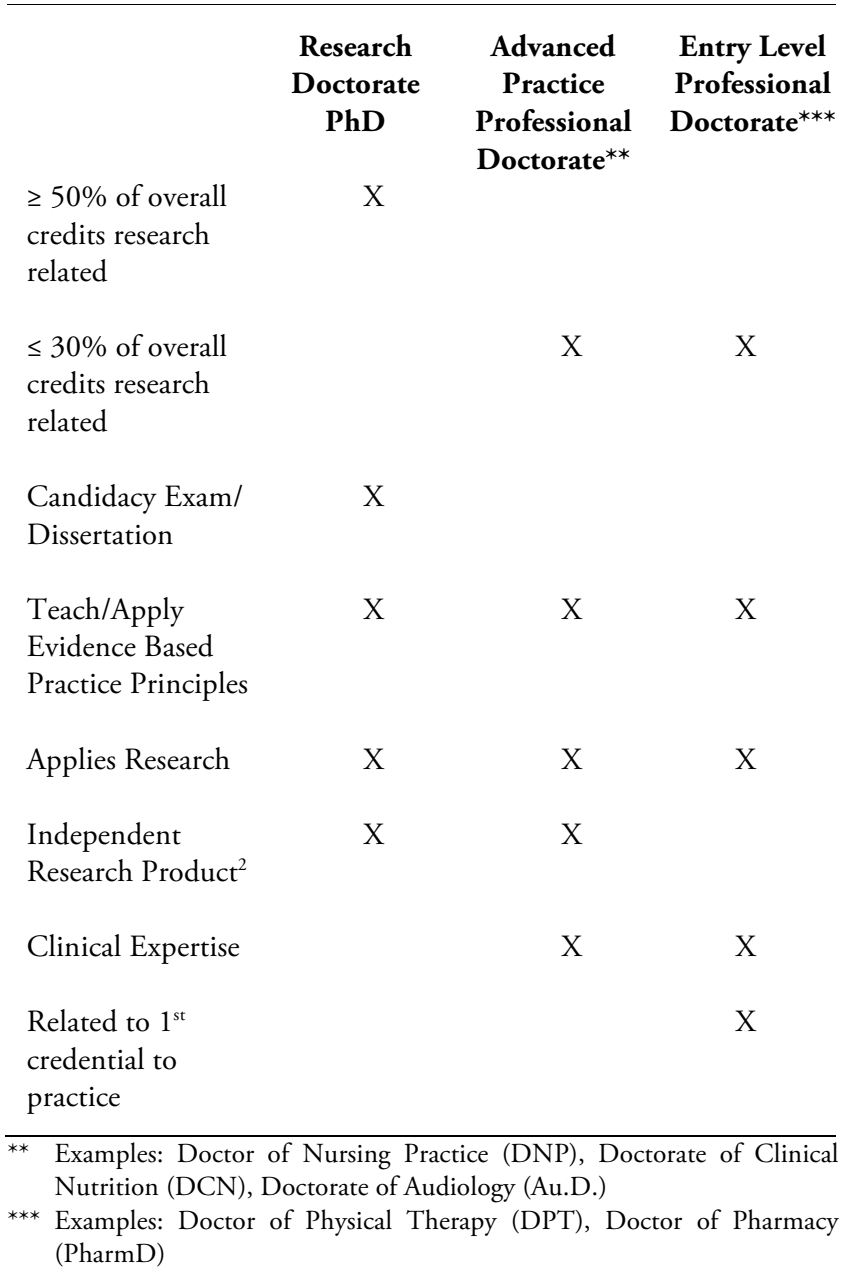

\section{DCLS PROGRAM IMPLEMENTATION}

The current climate in higher education is one of major change, with considerable focus on cost, full-time faculty vs part-time faculty, support staff, and tuition. ${ }^{18-23}$
Reductions in fund allocations at every level presents a challenge in implementing new programs. RutgersBiomedical and Health Sciences (RBHS) was an ideal setting for the development of this new degree. The university is a large health science center with over 35 programs in the allied health professions, as well as schools of medicine, dentistry, public health, nursing, pharmacy, and biomedical sciences. Rutgers-SHRP had precedence for offering practice and clinical doctorates, with the first Doctorate in Nutrition (DCN) offered in the United States (2003), and one of the first entry-level Doctorates in Physical Therapy (DPT). Faculty in SHRP had online education expertise, with online degree programs offered since the early 1990's. A selection of core online graduate courses offered to an interprofessional student pool had potential for incorporation into the CLS graduate curriculum, and, most important, there was strong support from the university and school administration for the DCLS program. This support is critical when developing a new program. A three phase development and implementation strategy was utilized. This approach provided a cost-effective model for the department to establish graduate programs, develop curriculum, increase the student pool, provide faculty development, and expand interprofessional education opportunities within SHRP and with other university units.

\section{PHASE I (2003-2006)}

Phase I began in 2003, with the development of the CLS graduate programs. The Department of CLS collaborated with the SHRP Department of Interdisciplinary Studies (IDS) in the development of a CLS track in the already approved and established online Master of Science in Health Sciences program (MSHS-CLS). The online delivery model for the theoretical courses, including live webinars, with emphasis on active learning strategies best meets the educational needs of the adult learner/certified professional employed in the field. The 30 credit CLS track utilized the Department of IDS's four established CORE interprofessional education courses (12 credits): Research Methods, Evidenced-based Literature Review, Health Services Issues and Trends, and Graduate Project. The CLS faculty began development and implementation of clinical laboratory science specialization courses (six courses). Phase I also included the development of a 12 credit (four courses) Graduate Certificate in Clinical Laboratory Science. This short 


\section{EDUCATION}

course of study offers MLS professionals the opportunity to enroll as non-matriculated students, and to determine if online education is an effective mode of learning for them. Credits earned in the Graduate Certificate in CLS can be applied to the MSHS-CLS. This was the first phase providing students a "steppingstone" model from certificate program, to the master program, to the DCLS.

The online format meets the need of the certified, employed, MLS professional, providing anytime, anyplace education via online delivery of theoretical courses in a structured, faculty-facilitated, highly interactive environment. A constructivist pedagogical framework, with an emphasis on directed study, an active learning method, is employed. It is studentcentered and provides for active student participation in creating the learning environment. The student engages the content via structured assignments and activities, and learns through information searching, problem solving, critical thinking, and discussion with classmates, faculty and peers including laboratory supervisors, administrators, pathologists, physicians, and other healthcare professionals. This method assures the rigor of the courses at a graduate level and enhances the high quality learning experience.

The interdepartmental collaboration provided improved avenues of communication between faculty, and increased opportunities for team-teaching and student interprofessional interaction. It also provided the platform to create a CLS graduate program as a track within an established and State-approved Master degree in health sciences without an extensive approval process. This was a cost-neutral approach utilizing established resources both within SHRP and within the Department of CLS. Phase I laid the foundation for the Department of CLS to move forward with curriculum and faculty development, with the goal to develop an educational ladder to the DCLS level.

\section{PHASE II (2006-2010)}

Phase II was a growth phase, highlighted by development of an additional seven CLS specialization courses for a total of 13 required and elective CLS courses. During Phase II increased collaboration in IPE courses, enrollment (70+ students), visibility/national recognition, and faculty participation with CLS colleagues on the ASCLS Professional Doctorate Task
Force also occurred. The program utilizes the existing Department of CLS faculty (full time and adjunct) and the existing department administrative support staff. The Department of CLS employs five full time doctoral level faculty, four PhDs and one MD pathologist. The online course delivery model enabled the CLS faculty to engage national and international experts in specific CLS disciplines and related fields as guest lecturers and adjunct faculty. In a traditional live classroom setting the opportunity to engage multiple national and international guest lecturers and adjunct faculty is a financial challenge. Realistically, a typical program budget would not support the costs (travel, lodging, meals, etc.) associated with engaging multiple guest lecturers for on-campus lectures and seminars. Utilizing technology as a lever to enhance the education experience, the online delivery of course content, and the use of live webinars via computer-based interactive sessions, provides students with an enhanced educational experience through the opportunity to interact with colleagues and renowned guest lecturers. This is a cost-effective approach which supplements the full time faculty staff and opens the door to increased student enrollment, thus increases student tuition revenues, which offsets the remuneration of guest and adjunct faculty.

\section{PHASE III (2010-2012)}

With the MSHS-CLS recognized, a pool of graduate students who could be a potential applicant pool for the DCLS, faculty experienced in graduate education and research, and interprofessional collaborations well established, the Department of CLS embarked on the final phase of the DCLS program development, approval and implementation. The DCLS program employs a blended/hybrid delivery model of online and live experiential learning. The theoretical courses are offered online and the program culminates in a one year full time clinical practice experience/residency at an affiliated clinical institution. During the clinical experience, students also conduct CLS outcomes/translational research to enhance the delivery of clinical laboratory services and patient care.

The DCLS competencies and recommended course descriptions developed by the ASCLS Professional Doctorate Task Force, and accepted by the Graduate Task Force of NAACLS were used as a guide in developing the DCLS program goals, objectives and 
courses. The general competencies achieved in course experiences center around the key concepts of patient care, interprofessional and communication skills, professionalism, outreach and continuous practice improvements. The DCLS program is 80 credits beyond the baccalaureate degree. The curriculum consists of four core components: Advanced Clinical Laboratory Science, Professional, Research, and Clinical Practice (Table 2).

Table 2. Rutgers-SHRP DCLS Curriculum Model

ADVANCED CLINICAL LABORATORY SCIENCE CORE (27
credits)
Molecular Diagnostics
Advanced Topics in Molecular Diagnostics
Advanced Hematology
Advanced Hemostasis
Transfusion Practice
Advanced Clinical Immunology
Advanced Topics in Clinical Chemistry
Infectious Disease
Overview of Disease Processes and Treatment

\section{PROFESSIONAL CORE ( 20 credits)}

Clinical Laboratory Utilization in Quality Healthcare Delivery

Laboratory Management and Regulatory Issues

Health Services Issues and Trends (IPE)

Health Epidemiology (IPE)

Clinical Laboratory Diagnosis Correlation

DCLS Seminar I*

DCLS Seminar II *

DCLS Seminar III *

\section{RESEARCH CORE ( 21 credits)}

Clinical Laboratory Data Analysis

Data Analysis and Interpretation I (IPE)

Principles of Translational and Outcomes Research in Clinical Laboratory Science

Evidenced-based Literature Review (IPE)

DCLS Research Project I*

DCLS Research Project II (continuation of research project) *

DCLS Research Project III ( completion of research project) *

\section{CLINICAL PRACTICE CORE (12 credits)}

DCLS Clinical Practice I*

DCLS Clinical Practice II *

DCLS Clinical Practice III *

* denotes courses taken during the full time clinical practice year

The Rutgers - SHRP DCLS curriculum builds on the MSHS-CLS curriculum developed in the Phase I and II. At the start of Phase III, 18 of the 28 courses for the DCLS were already established. The program approval process was a one year journey to meet the institution and state requirements, including program concept document, and a 25 step institutional and state approval process. This culminated with final approval in 2012.

\section{COLLEGIAL COLLABORATION}

Collaboration agreements for course and faculty resource sharing have been explored with institutions that offer graduate level courses in CLS or related subjects. Collaboration provides an enhanced education experience with opportunities to share expert faculty and courses, and is a cost-effective strategy. The ASCLS DCLS Oversight Committee supports the concept of collegial collaboration of resources and developed a DCLS National Course Bank. This course bank is under revision/update with a projected completion date of December 2014. An additional resource of CLS graduate programs is the ASCLS Online Graduate Program Directory. ${ }^{24}$

Many of the SHRP Department of CLS online graduate courses are offered to qualified professionals to enroll as a non-matriculated student. Several of the DCLS courses have been developed with the goal of achieving institutional collaboration with DCLS student interaction on a national level. For example, the DCLS Seminar courses explore a variety of specific topics and skills that a DCLS requires to function as a more active member of the interprofessional healthcare team. These include physical assessment, ethical issues in health care practice, principles of transcultural healthcare, patient interaction and communication skills, teaching strategies for health professions and the general public/patients, current topics and trends in CLS, and presentations related to clinical rounds, case studies and research/literature review/critiques. Most of these topics are pre-existing modules in specific Rutgers-SHRP courses, and course content and faculty sharing are utilized. The interdepartmental sharing of resources and faculty is another cost-effective and IPE strategy in program development and implementation. The educational experience for DCLS students could be enhanced through the inter-institutional sharing that could occur among various DCLS programs and DCLS students across the country. In particular, a live webinar approach with DCLS student presentations related to clinical rounding experiences and cases of interest would be an enriching experience.

\section{CLINICAL PRACTICE/RESIDENCY}

The culmination of the DCLS learning experience is the clinical practice/residency component. The SHRP- 
DCLS requires a one-year full time clinical practice at an affiliated clinical institution. The identification of clinical sites is a key component, as well as a challenge of program development and implementation. Networking among like-minded stakeholders including pathologists, laboratory and hospital administrators, and members of the healthcare team have presented several opportunities. Clinical affiliate agreements are in progress, with the initial locations in the northeast tristate area. The goal is to expand the network of affiliates nationally. This is another area of inter-institutional collaboration that would enhance the movement of establishing the DCLS as an active and key contributor on the interprofessional healthcare team.

\section{MLS CAREER LADDER}

In March of 2013 the MSHS-CLS was converted to a new degree designation, the Master of Science in Clinical Laboratory Science (MS-CLS). The rationale for the conversion of the MSHS-CLS track to the MS in CLS was; (1) an MS in Clinical Laboratory Science (MS-CLS) is more identifiable to practicing clinical laboratory professionals; (2) feedback from students and interested CLS professionals indicated a preference for a master's in clinical laboratory science rather than a generic health sciences master's degree; (3) offering a MS in CLS as a bridge between the BS in CLS and the DCLS would complete that continuum of education offerings for CLS professionals; (4) the Graduate Certificate in CLS is a bridge into the MSHS-CLS track and would be the bridge into an MS in CLS; (5) completion of courses in the MSHS-CLS is required for the DCLS. The MS-CLS degree is now solely offered by the Department of Clinical Laboratory Science, but retains key courses with interprofessional collaboration. With the implementation of the DCLS, the overall goal of the Rutgers-SHRP Department of CLS to offer a true career ladder for MLS professionals was achieved. The department offers a Bachelor in CLS (NAACLS approved), a Master in CLS, and the DCLS (Figure 1). The first DCLS student was accepted in Spring 2014 with a projected clinical residency beginning in Summer 2017. The next step in the strategic plan for the Rutgers-SHRP DCLS is to move forward with the NAACLS accreditation process.

\section{CONCLUSION}

The Rutgers-SHRP DCLS offers an innovative educational experience utilizing a blended pedagogy, distance education technology, and clinical experience. This design meets Rutgers-SHRP goals of creating an academic and clinical educational environment that values interdisciplinary education and practice, supports growth of scholarship and research, and increases opportunities for interdisciplinary and collaborative research. For educators interested in establishing a DCLS, exploring inter-departmental and inter-school collaborations for resource sharing (faculty and courses) is a critical initial step in the process, as well as interinstitutional outreach and collaboration.

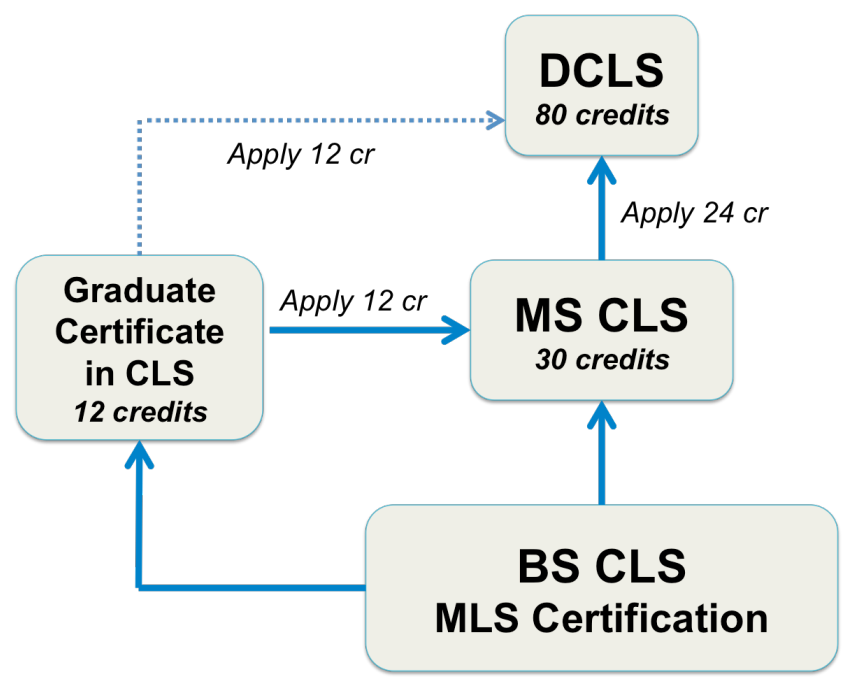

Figure 1. Career Ladder to the DCLS.

The preferred route (solid arrows) to the DCLS is the BS in CLS with MLS certification either directly to the MS in CLS or through the Graduate Certificate in CLS to the MS in CLS, then to the DCLS. Graduates of the MS in CLS can apply up to 24 credits towards the DCLS and would only have to take 56 additional credits to complete the DCLS. Students completing the Graduate Certificate in CLS can apply 12 credits to the MS in CLS or 12 credits directly to the DCLS. The alternate route to the DCLS (dashed arrow) is completion of the Graduate Certificate in CLS to the DCLS. One credit equals 45 hours of learning activity. Example: 3 credit course equates to approximately 135 hours of learning activity.

Abbreviations: $B S$ in $C L S$, baccalaureate degree in clinical laboratory science; $D C L S$, doctorate in clinical laboratory science; $M L S$, medical laboratory scientist; $M S$ in $C L S$, master of science in clinical laboratory science; $c r$, credit.

The development and implementation was achieved in a fiscally responsible, relatively cost neutral manner. The three phase process provided the resources, time, and skills to move forward into graduate education. The initial implementation of the program utilized the existing department faculty (full time and adjunct) and administrative support staff. The DCLS Program 
Director was selected from the current department faculty, and is also the MS-CLS and Graduate Certificate in CLS Program Director, providing a continuum of oversight for all the graduate programs. The major cost of the program is adjunct faculty to develop and teach several new courses and to assist in teaching online graduate courses. However, this has been added to the Department of CLS budget over the course of the years as each phase of development and implementation was executed, and was off-set by increased student tuition revenue as enrollment in the MS-CLS and Graduate Certificate in CLS increased. As expected, the addition of the DCLS program has had a positive impact on the enrollment in the MS-CLS and Graduate Certificate in CLS programs, 22\% increase and $77 \%$ increase respectively in the period Spring 2012-Fall 2014. The initial DCLS budget proposal included provisions to hire a 0.5 FTE faculty and a 0.5 FTE administrative assistant. With increased enrollment and thus an increase in tuition revenue, a budget revision approval was granted for a FT administrative assistant (hired), and a FT faculty. The program is currently seeking applicants for the FT faculty position.

The DCLS is the next option or "stepping-stone" in the education ladder offered by Rutgers-SHRP. The 12 credits earned in the Graduate Certificate in CLS can be applied to the MS-CLS, and up to 24 credits earned in the MS-CLS could apply to the DCLS. This model offers students the opportunity to acclimate to the online learning environment, and balance professional, personal and education responsibilities with full and part time options for degree completion. The development of a career ladder that spans the professional spectrum provides options and opportunities to retain the best and brightest professionals to continue their career in the CLS profession.

\section{REFERENCES}

1. Advanced Practice: DCLS position paper: Available from http://www.ascls.org/about-us/voice-your-opinion/positionpapers/176-advanced-practice-doctorate-in-clinical-laboratoryscience. Accessed 2014 July 7.

2. A clinical doctorate for the laboratory. NAACLS News Special Edition. 2006;92. Available from http://www.naacls.org/ PDFviewer.asp?mainUrl=/docs/naacls-news/vol92.pdf. Accessed 2014 July 7.

3. Guide to accreditation for doctorate programs in CLS. NAACLS accreditation information. Available from http://www.naacls.org/docs/guide_dcls.pdf. Accessed 2014 July 7.

4. CDC Division of Laboratory Systems, "The 2007 Institute: Managing for Better Health - Executive Summary of Action Plan Priorities". Personal Communication: Passiment, E. Exec. VP ASCLS, CDC Committee Member. http://www.cdc.gov/ ophss/csels/dlpss/eblm/index.html\#CLIHC

5. Weir, P. A family physician's perspective on laboratory testing and diagnostic errors. Clinical Laboratory News. 2013:39(1). Available from http://www.aacc.org/publications/cln/2013/ january/Pages/PSF-DiagnosticErrors.aspx\#. Accessed 2014 July 8.

6. Beck S, Doig K. Are new CLS practitioners prepared to stay? Clin Lab Sci 2007;20(3):161-71.

7. Fowler D, Martin T, Spence L. The clinical laboratory practitioner. Clinical Laboratory Science. 2005;18(4):199-202.

8. Frohman E. Clinical doctorate in laboratory science. Clin Lab Sci. 2005;18(4):198.

9. Laposata M. Patient-specific narrative interpretations of complex clinical laboratory evaluations: who is competent to provide them? Clin Chem 2004;50:471-2.

10. Laposata ME, Laposata M, Van Cott EM, et al. Physician survey of a laboratory medicine interpretive service and evaluation of the influence of interpretations on laboratory test ordering. Arch Path Lab Med. 2004;128(12):1424-7.

11. Leibach, EK. The doctorate in clinical laboratory science: a view of the strategy for continuity, growth, and realization of potential. Clin Lab Sci. 2007:20(3):189-92.

12. Leibach, E. K. The doctorate in clinical laboratory science: a projection of professional outcomes. Clin Lab Sci. 2007: 20(4):197-200.

13. Nadder $T$. The development of the doctorate in clinical laboratory science in the US. The Journal of the International Federation of Clinical Chemistry and Laboratory Medicine. 24(1). Available from http://www.ifcc.org/media/224753/ 07_Nadder.pdf. Accessed 2014 July 8.

14. Doig K, Beck S. Surveys of support for the doctorate in clinical laboratory science. Clin Lab Sci 2008;21(2):92.

15. Nadder TS. Results from an interest survey on the professional doctorate degree in CLS. ASCLS Today. 2011;XXV(4):13-4.

16. Council of Graduate Schools. Available from http://cgsnet.org/ ckfinder/userfiles/files/PubOrderForm_November2012.pdf. Accessed 2014 July 15.

17. Association of Schools of Allied Health Professions. Descriptive differentiation of clinical doctorates position statement of the Association of Schools of Allied Health Profession. Available from http://www.paeaonline.org/index.php?ht=a/GetDocumen tAction/i/68613. Accessed 2014 July 15.

18. Desrochers, DM, Kirshstein, R. Labor intensive or labor expensive? changing staffing and compensation patterns in higher education. American Institute for Research Delta Cost Project. 2014. Available from http://www.deltacostproject.org/ sites/default/files/products/DeltaCostAIR_Staffing_Brief_2_3_ 14.pdf Accessed 2014 July 16.

19. Kirshstein R, Wellman, Technology and the broken higher education cost model: insights from the Delta Cost Report. J. EDUCAUSE Review. 2012;47(5):12-4,16,18,20,22

20. Randel D. The market made me do it. Liberal Education. 2012;98(3):6-13. Available from: ERIC, Ipswich, MA. Accessed 2014 July 16. 
21. Wellman J. Improving data to tackle the higher education "cost disease". Planning for Higher Education. 2010;38(3):25-37. Available from: ERIC, Ipswich, MA. Accessed 2014 July 16.

22. Boulard G. Sticker shock: state funding cuts lead to sharp tuition hikes at Florida colleges. Diverse: Issues In Higher Education. 2011;28(12):15-6. Available from: ERIC, Ipswich, MA. Accessed 2014 July 16.

23. Lebeau Y, Stumpf R, Brown R, Lucchesi M, Kwiek M. Who shall pay for the public good? Comparative trends in the funding crisis of public higher education. Compare: A Journal of Comparative And International Education. 2012;42(1):13757. Available from: ERIC, Ipswich, MA. Accessed 2014 July 16.

24. ASCLS Directory of CLS \& CLS Graduate Programs. Available from http://www.ascls.org/images/student_pdfs/ ASCLS_Online_Directory_MLS_Dec_2013.pdf Accessed 2014 July 17.

\section{CLEC 2016 CALL FOR ABSTRACTS}

The deadline for abstracts for poster presentations or technology demonstrations at the 2016 ASCLS Clinical Laboratory Educators Conference (CLEC) is October 1, 2015.

Submission instructions and the proposal form may be found at www.ascls.org/CLEC. The completed proposal form and abstract must be submitted electronically by the deadline.

The 2016 CLEC will be held February $25-27^{\text {th }}$ in Minneapolis, MN. Additional meeting information will be available at www.ascls.org/CLEC. 